\title{
THE LABOUR SUPPLY AND SAVINGS EFFECTS OF SUPERANNUATION TAX CHANGES*
}

\author{
JOHN CREEDY \\ University of Melbourne \\ ROSS GUEST \\ Griffith University
}

\begin{abstract}
This paper investigates the effects on labour supply, consumption and savings of a change in the superannuation tax structure, involving the taxation of contributions to a fund, pre-retirement earnings of the fund, and the benefits received from the fund during retirement. The effects on lifetime plans of tax changes are investigated using a simple three-period model in which the final period is retirement. The effects of unanticipated changes, requiring revisions to plans, are examined. Although the partial effects of particular tax changes are unambiguous, the effects of allowing for a government budget constraint mean that it is difficult to predict a priori how labour supply is likely to be affected. However, private savings unambiguously fall.
\end{abstract}

\section{I NTRODUCTION}

This paper examines the labour supply and savings effects of a change in superannuation taxation. The labour supply effects of taxes on superannuation can take several forms because of the existence of three separate stages at which superannuation is taxed, including the contributions to a superannuation fund, the earnings obtained by the fund, and the income withdrawn from the fund after retirement. For example, a system is of the TTT variety if tax is imposed in all three stages. ${ }^{1}$ When compulsory superannuation was introduced in Australia, the TTT structure was adopted, making it the only OECD country with this form. The most common scheme in the OECD is EET, where contributions and fund earnings are exempt and only benefit income post retirement is subject to taxation. However, in the 2006 Australian Government Budget benefits after retirement were made exempt from taxation, with the new rules taking effect on 1 July $2007^{2}$

A complete analysis of the effects of changes in taxation, on individuals at various stages of the life cycle at the time of the change, requires a complex model of lifetime optimisation along with a method of dealing with the potential general equilibrium effects and the government's budget constraint. The latter is relevant since the elimination of taxation on superannuation benefits obviously means that at least one other tax rate must be increased or other transfer payments or expenditures reduced. The effects on individuals at a given stage of their life cycle was analysed by Atkinson, Creedy and Knox (1996) using the LITES microsimulation model. Their focus in particular was on within-generation inequality implied by alternative retirement income strategies. But their model did not allow a general equilibrium analysis or an analysis of inequality between generations. Rather than to apply a complex general equilibrium analysis of life cycle effects, the modest aim of the present paper is to provide a preliminary analysis using a highly simplified model of lifetime labour supply and consumption. Despite the simplicity of the model, it seems useful to consider the potential direction of changes in behaviour resulting from a superannuation tax change. 
In particular, the model can be used to investigate the extent to which the direction of some changes can be anticipated a priori, without the need for detailed empirical estimates. The model also has the potential to be extended and used as one component of a larger and more comprehensive model.

The model is set out in Section II. The lifetime is modelled as consisting of three stages, the last of which is retirement. Hence it is not possible to use the model to examine questions relating to the age of retirement, which may be affected by an unanticipated change in policy. But the effects on pre-retirement labour supply and savings, other than the compulsory super-annuation contribution, can be investigated. Section III then shows how the effects of tax policy changes on those in the middle stage of the life cycle can be examined. Some illustrative numerical examples are reported in Section IV and brief conclusions are in Section V.

\section{The Lifetime M odel}

This section presents the basic model used to examine the effects on an individual's labour supply and consumption decisions of alternative tax structures. Suppose the lifetime is divided into three periods, with work in the first two periods and retirement in the final period. The exogenous wage rates in the two working periods are $w_{1}$ and $w_{2}$. There is a compulsory superannuation system, as in Australia, whereby individuals must contribute a proportion, $x$, of pre-tax earnings to a fund. These contributions are taxed at the fixed rate, $t_{c}$, while the fund's earnings are taxed at the rate, $t_{y}$. The benefits received by the fund at retirement are then taxed at the rate, $t_{b}$. This framework therefore corresponds to a simple TTT system. ${ }^{3}$ Income tax is imposed at a constant proportional rate, $t$, on earnings and interest income arising from additional savings during the first two periods. The exogenously fixed rate of interest is equal to $r$. Subsection 2a) examines the budget constraint facing the individual. Subsection $2 \mathrm{~b}$ ) considers lifetime utility maximisation.

\section{a) The lifetime budget constraint}

Consumption and leisure in each period are $c_{j}$ and $h_{j}$, for $j=1, \ldots, T$, with $T=3$. The individual's time endowment in each period is one, and the price of goods in each period is normalised at one. During retirement, $h_{3}=1$. Private savings are treated as being made out of post-income-tax income and accumulate at the post-tax interest rate. It is assumed that earnings, contributions and so on are made at the beginning of each period.

\footnotetext{
${ }^{3}$ See Kingston and Piggott (1993) for an analysis of equivalence relationships among the three tax rates $t_{c}, t_{y}$ and $t_{b}$.
} 
Table I Income flows

From period 1

Net earnings

Net contrib to fund in 1

Net inc of fund in 1

Fund at end of 1

Net inc of fund in 2

Fund at end of 2

$$
\begin{aligned}
& w_{1}\left(1-h_{1}\right)(1-x)(1-t)=Y_{1} \\
& x w_{1}\left(1-h_{1}\right)\left(1-t_{c}\right)=B_{1} \\
& r x w(1-h)\left(1-t_{c}\right)\left(1-t_{y}\right)=B r^{*} \\
& B_{1}\left(1+r_{y}^{*}\right) \\
& B_{1}\left(1+r_{y}^{*}\right) r_{y}^{*} \\
& B\left(1+r^{*}\right)^{2} \\
& \quad 1 \\
& w_{2}\left(1-h_{2}\right)(1-x)(1-t)=Y_{2} \\
& x w_{2}\left(1-h_{2}\right)\left(1-t_{c}\right)=B_{2} \\
& r x w_{2}(1-h)\left(1-t_{c}\right)\left(1-t_{y}\right)=B r_{2}^{*} \\
& B\left(1+r^{*}\right)
\end{aligned}
$$

From period 2

Net earnings

Net contrib to fund in 2

Net inc of fund in 2

Fund at end of 2

The two relevant after-tax interest rates are denoted by $\quad r_{y}^{*}=r\left(1-t_{y}\right)$ and $r^{*}=r(1-t)$. As in standard labour supply models, the objective is to express the budget constraint in terms of the individual's 'full income'. In this context, full income is the present value of income from all sources, if the individual devotes all the endowment of time to work during the first two periods of the life cycle. This is treated as if it were spent on goods and leisure, where the latter is priced at the net wage. It is useful to consider the relevant income flows, in particular those involving the superannuation fund. These flows are shown in Table I. The first part of the table shows the accumulation of the fund, over two periods, arising from earnings obtained during the first period. The second part of Table I shows the contribution to the fund arising from earnings during the second period.

The lifetime budget constraint, assuming there are no inheritances or bequests, is thus expressed as:

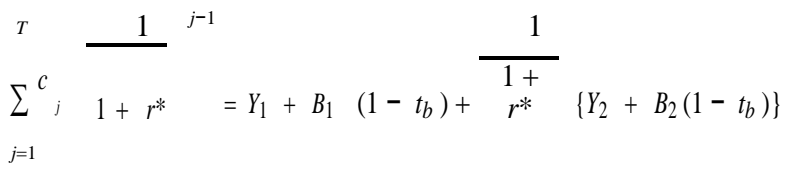

Hence:

$$
\begin{gathered}
\sum_{j=1}^{T}{ }_{j}^{c}{\stackrel{1}{1+r^{*}}}^{j-1}=\sum_{j=1}^{T-1} \underbrace{j-r^{*}}{ }^{j-1}\left(Y_{j}+B_{j}\left(1-t_{b}\right)\right) \\
=\sum_{j=1}^{T-1} \underbrace{j-1} w_{j}\left(1-h_{j}\right) E_{j}
\end{gathered}
$$

where the term $E_{j}$ is given by:

$$
E_{j}=(1-t)-x(1-t)-\begin{array}{r}
1+r * y \\
1+r^{*}
\end{array} \quad\left(1-t_{c}\right)\left(1-t_{b}\right)
$$

The lifetime budget constraint can therefore be expressed as:

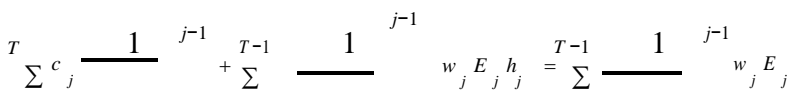


The left hand side of (4) represents the present value of consumption, including goods and leisure. Hence, the price of leisure, $p_{h, j}$, in period $j$ is given by:

$$
p_{h, j}={\frac{1}{1+r^{*}}}^{j-1} w_{j} E_{j}
$$

The right hand side of (4) is full income, denoted $M$. It is a simple matter to add a government non-means-tested benefit of, say $b$, each period, whereby $M$ becomes:

$$
\underset{j=1}{M}=\frac{T-1}{\sum} \sum^{j-1} w_{j} E_{j} \quad r_{j=1}^{+b_{\Sigma}}{\frac{1}{1+r^{*}}}^{j-1}
$$

It is clear from the form of the budget constraint that a change in any tax rate has both an income and price effect. For example an increase in the income tax rate, $t$, implies a reduction in full income, which may typically be expected to have a negative effect on leisure and hence a positive effect on labour supply. However, the increase in $t$ also reduces the price, that is the opportunity cost, of leisure, leading to an increase in the demand for leisure and hence a reduction in labour supply. The two effects therefore have opposing effects on labour supply. Further analysis requires the specification of lifetime utility.

\section{b) Utility maximisation}

As in the standard discounted utility model, suppose the individual maximises a lifetime utility function of the form:

$$
{ }_{j=1}^{U}={ }^{T} \frac{1}{1+\rho}^{j-1} U\left(c_{j}, h_{j}\right)
$$

where the pure time preference rate is equal to $\rho$. For convenience, within-period utility is assumed to follow the Cobb-Douglas form:

$$
U\left(c_{j}, h_{j}\right)=c a_{j} h_{j}^{1}-\alpha
$$

for $j=1$, 2, so that $U\left(c_{3}, 1\right)=c_{3}{ }^{\alpha}$. Taking the logarithmic transformation of $U\left(c_{j}, h_{j}\right)$ and substituting into (7), the sum of the coefficients on log-terms, $\Phi$, is:

$$
\Phi=1+\frac{1}{1+\rho}+\frac{1}{1+\rho}{ }^{2}
$$

Using the standard Cobb-Douglas result that the optimal value for any variable is the ratio of the coefficient on that variable to the sum of coefficients, multiplied by the ratio of full income to the relevant price, consumption in each period is therefore given by:

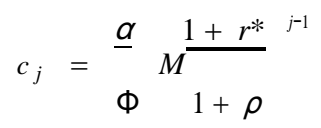

for $j=1, \ldots, T$. Similarly leisure in each period is given by:

$$
h_{j}=\frac{1-\alpha}{\Phi} \frac{M}{w_{j} E_{j} 1+\rho}{\frac{1+r^{*}}{j-1}}^{\frac{1}{1+\rho}}
$$


for $j=1$, 2. It is assumed that parameters and variables are such that $h_{1}<1$ and $h_{2}<1$, otherwise the treatment of corner solutions involving non-participation in the labour market involve considerable complexities.

The effect on leisure demand in any period of a change in, say, the income tax rate, $t$, can be expressed by differentiating (11) with respect to $t$, so that:

$$
\frac{\partial h_{j}}{\partial}=\frac{h_{j}}{M a}-\frac{\partial}{M} h_{j}-\frac{\partial p_{h, j}}{p_{h, j} \quad \partial}
$$

Dividing both sides by $h_{j}$ shows that the proportional change in leisure demand, in response to a change in the tax rate, is equal to the proportional change in full income minus the proportional change in the relative price of leisure.

Private voluntary savings, $s_{j}$, in period $j$ (that is not including the compulsory superannuation contributions) are equal to net income minus consumption, so that:

$$
s_{j}=Y_{j}+b-c_{j}
$$

Substitution for $Y_{j}$ and $c_{j}$ and differentiation shows that $\partial s_{j} / \partial t$ is a complex function of all the parameters in the model, but is negative.

\section{A POLICY CHANGE}

This section considers the effects of introducing a tax policy change. Suppose that the tax rafe on superannuation benefits from the fund is changed to $t_{b}$, at the start of a period. If

$t_{b}=0$, this corresponds to a movement from a TTT to a TTE system. For aggregate tax revenue neutrality, at least one other tax rate must also be changed; suppose the rate on earnings from employment is adjusted to $t^{\prime}$. Consequently, $r^{*}$ is adjusted to $r^{\prime *}$. The following results can easily be modified for changes to other rates. For simplicity, any potential general equilibrium effects on wage rates and interest rates are ignored here.

From the point of view of those at the start of the life cycle when the policy comes into effect, there is no need to modify the results obtained above, since their plans are simply made using the new rates. For those entering retirement when the policy is announced, labour supply and consumption decisions in the previous two stages have already been made, so the only adjustment is to consumption during retirement. Such individuals experience an unequivocal gain. The more complex effect is on those starting the second period when tax rates change. This is examined in the following subsection.

\section{a) Effects of unanticipated tax changes}

Consider the problem of deciding on consumption in periods 2 and 3, and labour supply in period 2, given that a choice was made in the first period based on different tax rates. First the new budget constraint for this two-period problem must be obtained.

The retirement fund at the start of period 3 arising from contributions from the first period's earnings, $Q$, is given by:

$$
Q=B_{1}\left(1+r^{*}\right)^{2}
$$

In addition, the private savings made during period 1 produce accumulated private savings at the start of period 2 of: 


$$
S=\left\{Y_{1}+b-c_{1}\right\}\left(1+r^{*}\right)
$$

The new budget constraint, ignoring transfer payments for the moment, is thus:

$$
\begin{gathered}
{ }_{j=2}^{T} \quad c^{\prime} \frac{1}{1+r^{\prime *}}= \\
\quad+w^{j-2}=\left(1-h^{\prime}\right)(1-x)\left(1-t^{\prime}\right)+S+\frac{1}{1+r^{\prime *}}\left[Q\left(1-t^{\prime}\right)\right. \\
\left.+\left\{x w_{2}\left(1-h_{2}^{\prime}\right)\left(1-t_{c}\right)\left(1+r_{y}^{*}\right)\right\}\left(1-t_{b}^{\prime \prime}\right)\right]
\end{gathered}
$$

where, as with the tax rates, a prime attached to a variable indicates that it is a new value resulting from revised plans following the unanticipated tax change. The right hand side of (16) consists of earnings in period 2, net of income tax (at the new rate) and mandatory superannuation contributions, along with (the present value at period 2 of ) accumulated superannuation contributions (arising from those already made in period 1 as well as new contributions in period 2). The constraint thus becomes:

$$
{ }_{j=2}^{T} c_{z=}^{\prime}{\frac{1}{1+r^{\prime *}}}^{j-2}=\frac{1}{1+r^{\prime *}} Q\left(1-t^{\prime}\right)+S+w\left(1-h^{\prime}\right) E^{\prime}
$$

where the new value of $E_{2}, E_{2}{ }^{\prime}$, is given by:

$$
E^{\prime}=\left(1-t^{\prime}\right)-x\left(1-t^{\prime}\right)-\frac{*}{1+r^{\prime *}}(1-t)\left(1-t^{\prime}\right)
$$

and:

$$
{ }_{j=2}^{T} c_{2}^{\prime}{\frac{1}{1+r^{\prime *}}}^{j-2}+w \underset{2}{E^{\prime} h^{\prime}=M^{\prime}}
$$

where $M^{\prime}$ is full income for this revised problem and is given by:

$$
M^{\prime}=\frac{1}{1+r^{\prime *}} Q\left(1-t_{b^{\prime}}\right)+S+w_{2} E_{2}^{\prime}
$$

This is finally augmented by the term $b \Sigma_{j=1}^{2}\left[1 /\left(1+r^{\prime *}\right)\right]^{j-1}$, which must be added to allow for transfer payments during the second and third periods.

The problem at the start of the second period is thus to maximise:

$$
U^{\prime}=U\left(c_{2}^{\prime}, h_{2}^{\prime}\right)+\frac{1}{1+\rho} U\left(c_{3}^{\prime}, 1\right)
$$

The sum of coefficients on log-values in this two-period utility function is given by $\Omega=1+\alpha$ / (l $+\rho$ ). Hence, consumption is given, for $j=2$, 3 , by:

$$
c_{j}^{\prime}=\frac{a}{\Omega}{\frac{M^{\prime}}{1+r^{\prime *}}}^{j-2}
$$


The revised value of leisure in the second period becomes:

$$
h_{2}^{\prime}=\frac{1-\alpha}{\Omega} \frac{M^{\prime}}{w_{2} E_{2}{ }^{\prime}}
$$

These results can then be used to obtained the revised value of private savings in the second period, as the difference between net income and consumption.

\section{b) The government's budget constraint}

The previous subsection has examined the revised plans of an individual at the start of period 2 when new values of $t_{b}$ and $t$ are introduced. It is a simple matter to revise the above expressions for changes in another tax rate, or indeed a combination of all other tax rates, in response to a change in $t_{b}$. The main point is that the government is subject to a budget constraint of some kind. It is also possible to envisage the government as being able to finance a reduction in revenue from one tax by borrowing, though this may be subject to a borrowing constraint and a specific time period over which the budget must be balanced. This would introduce substantial complexities. In tax modelling it is usual to impose revenue-neutral, or deficit-neutral changes.

In the present model, where there are labour supply responses to tax changes and more than one cohort is alive at any one time, the budget constraint, however specified in detail, would be highly nonlinear. Its construction also involves the precise specification of population heterogeneity, as aggregation over individuals is required, and this means that allowance must be made for some individuals being below the wage threshold above which $h<1$ in each period. If low wage individuals may not participate in one or more of the first two periods, depending on wage rate dynamics, the analysis of labour supply actually becomes a complex programming problem. ${ }^{4}$ Hence it is not possible to obtain expressions for the change in one tax rate consequent on a change in another tax rate or government transfer payment. However, further progress may be made in view of the fact that the direction of changes is often unambiguous, although the order of magnitude depends on many complex factors.

For example, consider, as above, the change in an individual's labour supply resulting from a change in $t_{b}$, accompanied by a change in $t$ designed to achieve aggregate revenue neutrality. Suppose that net revenue from the tax and transfer system (over a specified period and population group) is denoted $R$. The revenue neutral change in $t$ may thus be denoted ( $\left.d t / d t_{b}\right)\left.\right|_{R}$. Clearly, if $t_{b}$ is reduced, $t$ must be increased by an appropriate amount to compensate for the lost revenue from taxing superannuation benefits, so that $\left.\left(d t / d t_{b}\right)\right|_{R}<0$. The change in labour supply can be divided into two partial changes, along with the relationship between tax rates, as follows:

$$
\frac{d h_{2}}{d t_{b}}=\frac{\partial h_{2}}{\partial t_{b}}+\left.\frac{\partial h_{2}}{\partial} \frac{d t}{d t_{b}}\right|_{R}
$$

Given a clear idea of the sign of the tax change, along with an idea of the partial effects on labour supply of the separate taxes, it is therefore possible to examine whether or not an unambiguous change in labour supply is to be expected. As mentioned above, determination of the size of ( $d t$ $\left./ d t_{b}\right)\left.\right|_{R}$, dictated by the revenue-neutrality requirement, depends on a large number of factors, including the sizes of different cohorts existing at any time, the distribution of wage rates for each time and cohort, including the life cycle pattern of wage, the nature of preferences (and any differences among cohorts) and of course the extend of labour supply responses

${ }^{4}$ For an algorithm and discoussion in the context of two periods, see Creedy (1996, chapter 12). 

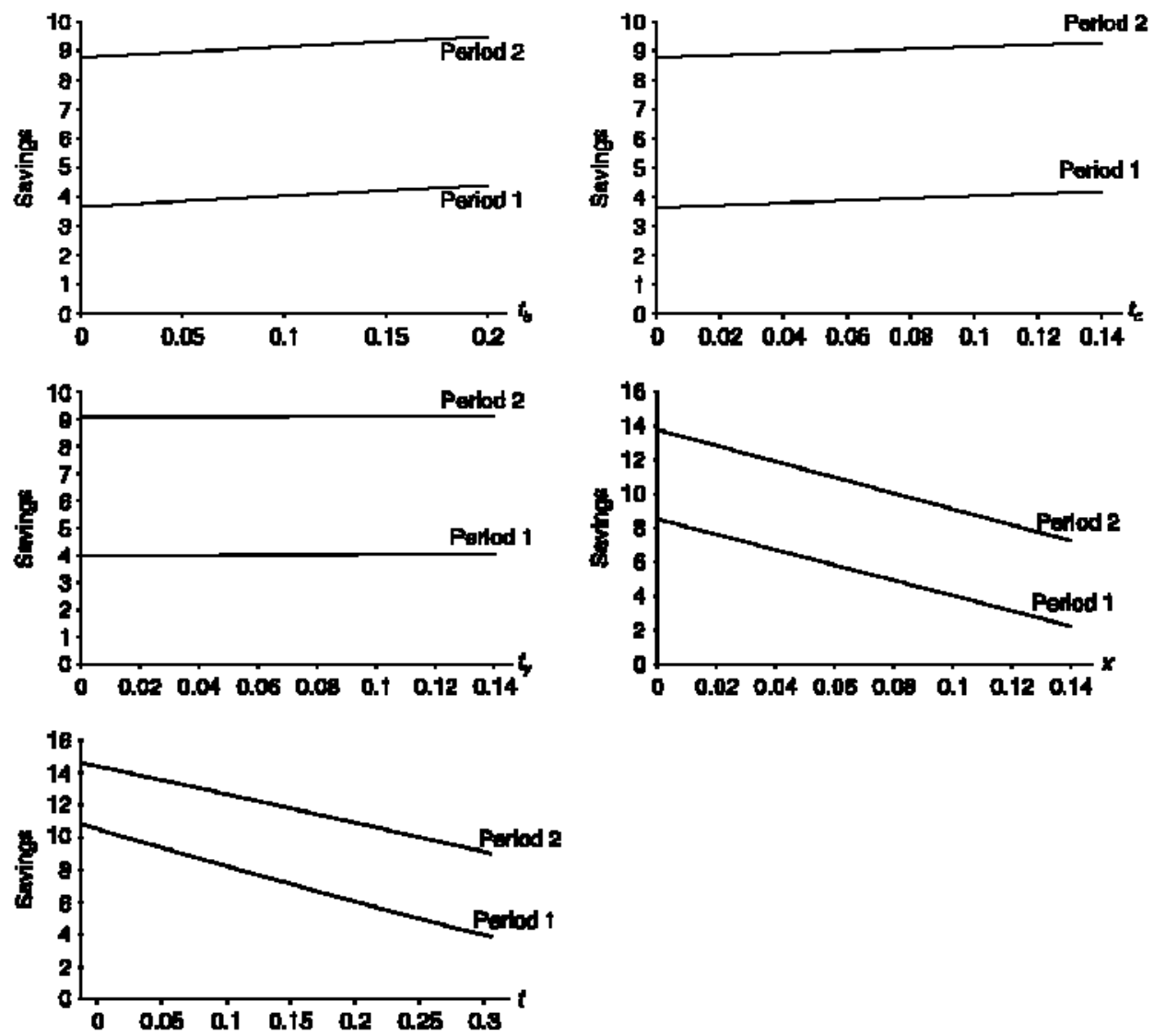

Figure 1. Private savings

themselves. In the absence of a specification of these additional elements, the approach adopted below is to consider the relevant partial terms and to examine the extent to which the direction of any changes may be unambiguous.

\section{Some Numerical Examples}

This section considers the properties of the model considered above, using numerical examples. Consider a single individual with $w_{1}=w_{2}=100$, and with a time preference rate of $\rho=0.14$. This high value is appropriate in view of the fact that the lifetime is compressed into just three periods, so that it is not an annual rate. Suppose also that the rate of interest is $r=0.10$ and that the transfer payment in each period is equal to $b=25$. To take a set of 'benchmark' tax rates, let $t=0.3$ and $t_{c}$ $=t_{y}=t_{b}=0.10$. The compulsory superannuation contribution in the benchmark case is assumed to be $x=0.10$. When lifetime plans are made subject to these rates, the fact that time preference exceeds the rate of interest means that optimal consumption falls over time: it 

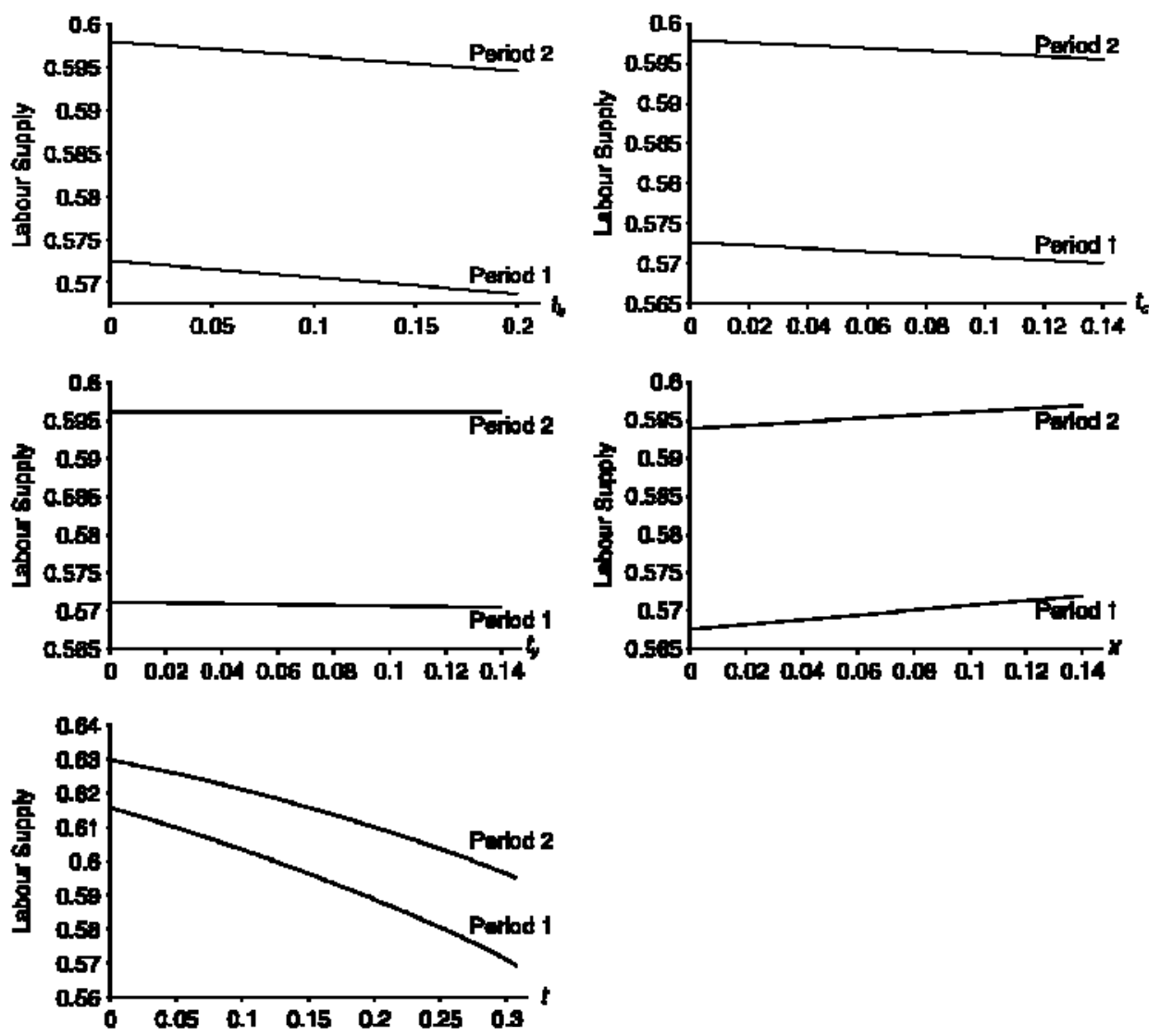

Figure 2. Labour supply

takes the values $56.92,53.43$ and 50.15 for periods 1,2 and 3 respectively. Labour supply is 0.57 and 0.60 respectively in the first and second periods, while private savings in the first two periods are 4.03 and 9.13 .

\section{a) Complete life-cycle plans}

The effects of variations in each of the tax and contribution rates in isolation, where all other values are held constant at their benchmark values, are shown in Figures 1, 2 and 3. These diagrams show, for each period, the variations in savings, labour supply and the 'price of leisure', as the relevant tax or contribution rate increases. For example, the top left hand segment of Figure 1 shows the variation in the individual's private savings (that is, excluding compulsory superannuation contributions) in periods 1 and 2 as the tax rate on superannuation benefits increases, with all other parameters fixed at their benchmark values. Private savings in period 1 are consistently below those of period 2, in view of the assumptions regarding time preference and the rate of interest. The diagrams show that a reduction in the tax rate on superannuation 

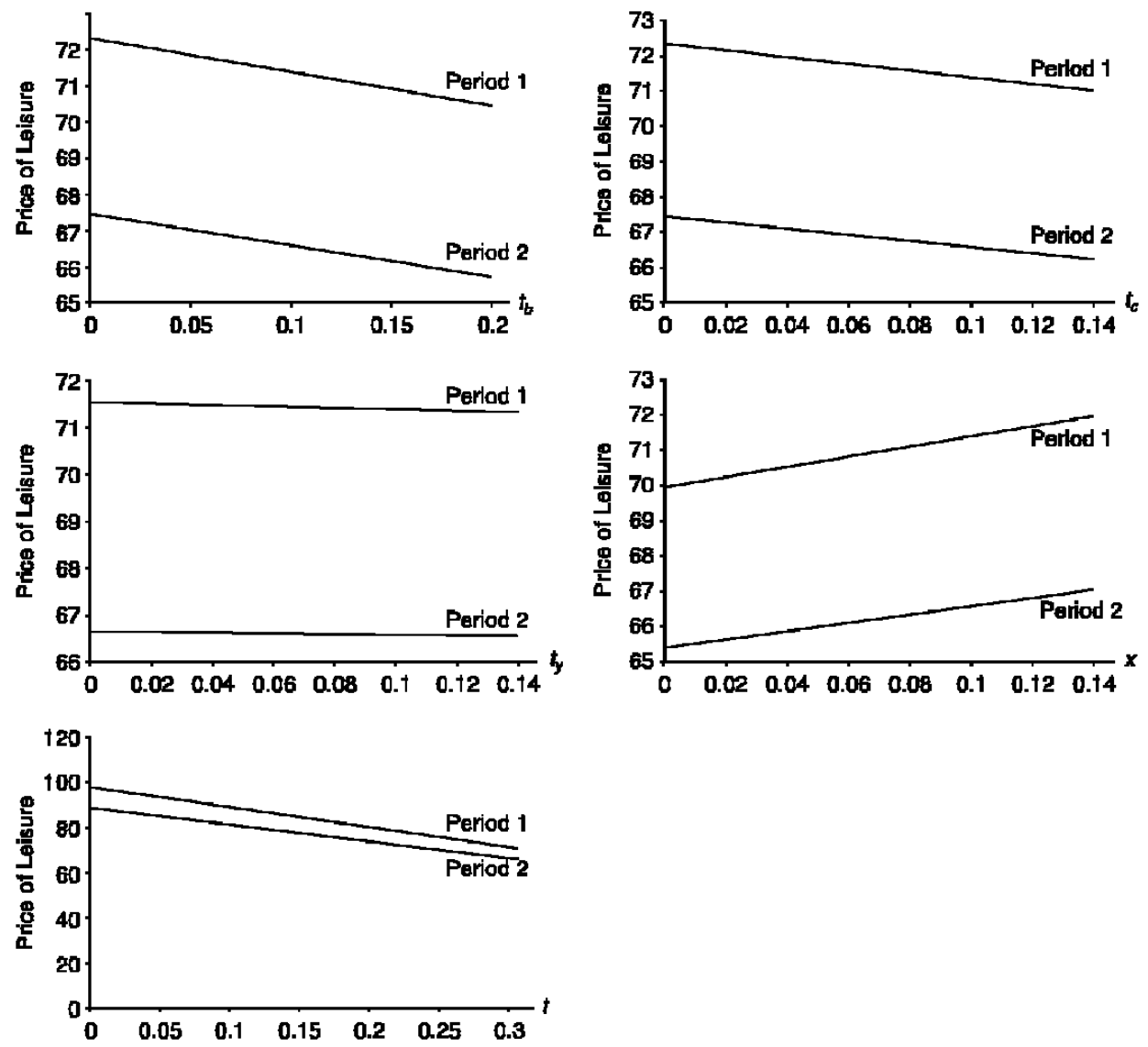

Figure 3. The price of leisure

benefits reduces private savings while increasing labour supply in each period of the working life, as the price of leisure increases.

The changes shown in these figures are comparative static in nature: they indicate how each variable 'responds' to changes in a single tax or contribution rate, when the optimal plans of such an individual are made at the beginning of the life cycle with full knowledge of those rates. They can be used to give some idea of the effects on an individual at the start of the life cycle of a change in the tax structure, using the kind of relationship shown in equation (24). For example, an increase in $t_{b}$ can, on its own, be seen to result in a reduction in labour supply in both periods. Also, the partial effect of a rise in $t$ is to reduce labour supply in both periods. The government budget constraint implies that $t$ and $t_{b}$ must change in opposite directions, as $\left(d t / d t_{b}\right) \mid{ }_{R}<0$; therefore a revenue neutral change in $t_{b}$ does not give an unambiguous change in labour supply.

However, the effect on private savings is clear $a$ priori, since a reduction is $t_{b}$ on its own leads to a reduction in private savings, while the increase in $t$ also leads to a reduction in private savings. Hence, irrespective of the size of the various effects, including the precise tax changes needed, 

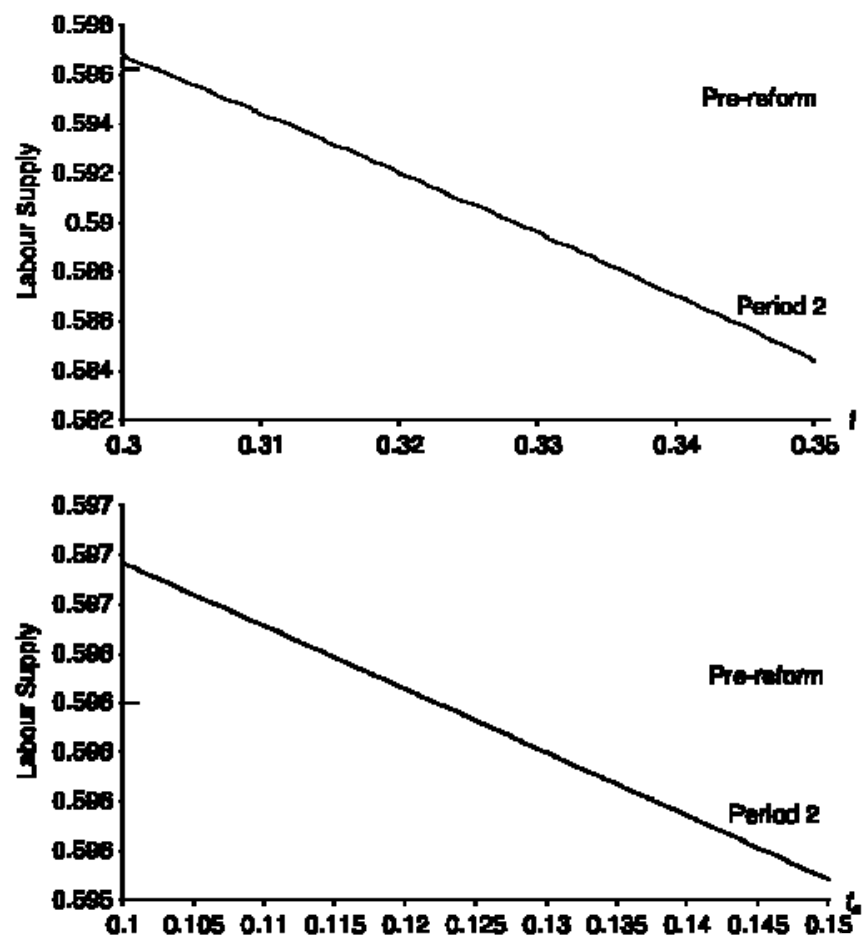

Figure 4. Labour supply following change to TTE

it can be said that a revenue-neutral reduction in $t_{b}$ reduces private savings for those at the beginning of the life cycle when the change takes place; that is, savings are lower than they otherwise would be, without the policy change.

\section{b) Unanticipated changes}

Consider next the effects of a change in the tax rate on superannuątion benefits, as it applies to an individual who is entering the second stage in the life cycle. Let $b \quad 0$, representing a move from a TTT to a TTE system. Figures 4, 5 and 6 show, respectively, the revised period-2 values of labour supply, the price of leisure and private savings. Each figure shows, as a horizontal line, the pre-reform planned value for period 2, made at the start of period 1 . The first part of each diagram shows the effect of combining $t_{b}{ }^{\prime}=0$ with a new value of income tax, $t$, and the second part shows the effect of combining $t_{b}=0$ with a new value of the tax rate on superannuation contributions, $t_{c}{ }^{5}$ The starting point for each tax rate (that is the initial value of the relevant tax rate indicated on the horizontal axis) is the benchmark rate indicated above. For example the top part of Figure 4 indicates that the abolition of the tax on benefits from the superannuation

${ }^{5}$ The revised values of labour supply and savings in period 2 were found to show very little sensitivity with respect to changes in $t_{y}$, and are therefore not shown here. 

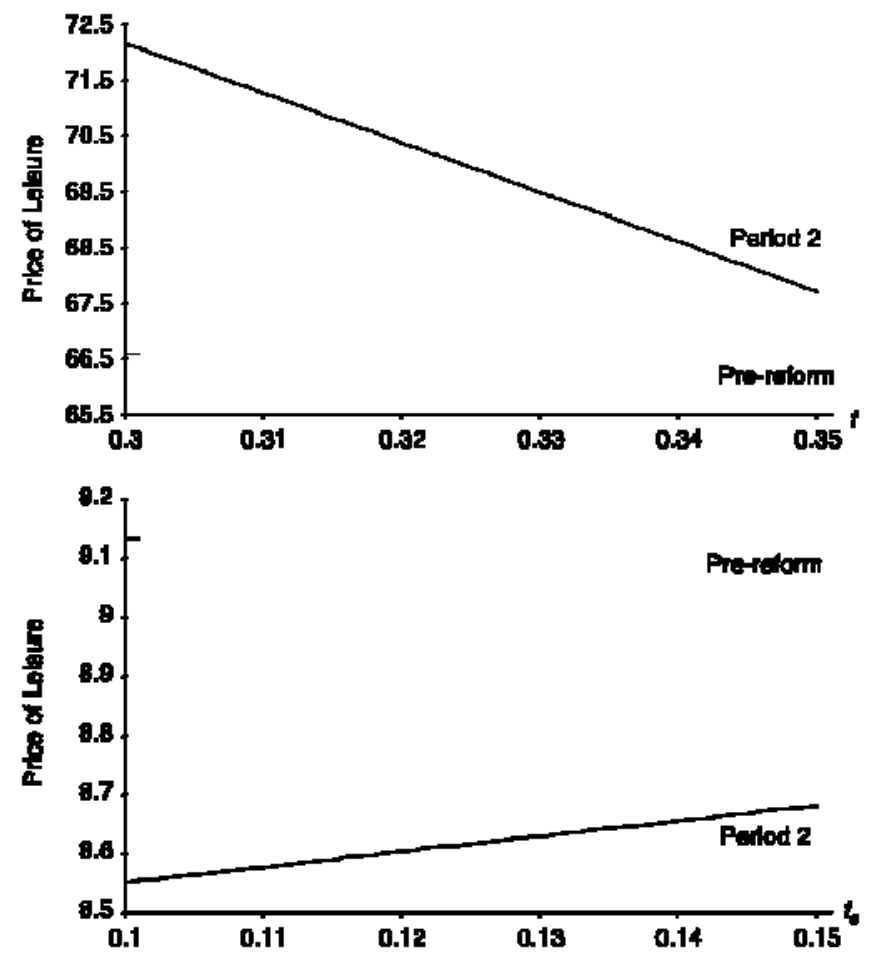

Figure 5. The price of leisure following change to TTE

fund during retirement produces, on its own, an increase in labour supply. But the resulting increase in $t$, required to achieve revenue neutrality, produces, as a partial effect, a reduction in labour supply. Hence the move to TTE can increase labour supply in period 2, compared with the pre-reform plan, only if it is accompanied by a very small increase in $t$. The effect on labour supply cannot therefore be predicted a priori - considerable information is needed merely to predict the direction of the change.

However, from Figure 6 it can be seen that private savings in period 2 unequivocally fall, compared with the pre-reform plans, as a result of the combined effect of the drop in $t_{b}$ to zero combined with an increase in $t$ : this is because both the drop in $t_{b}$ and the increase in $t$ have the same partial effects. When a policy shift from TTT to TTE is accompanied by an increase in $t_{c}$, required for revenue neutrality, the partial effects on saving plans do not move in the same direction. Nevertheless, it can be seen that a substantial increase in $t_{c}$ would be require for savings in period 2 to increase relative to pre-reform plans.

\section{CONCLUSIONS}

This paper has provided a three-period analysis of anticipated and unanticipated changes in the taxation of superannuation. In particular it has analysed the effects on an individual's labour supply, consumption and private saving behaviour in the first two periods of the life cycle of tax changes. Particular attention was given to the case where the individual is in the middle stage 

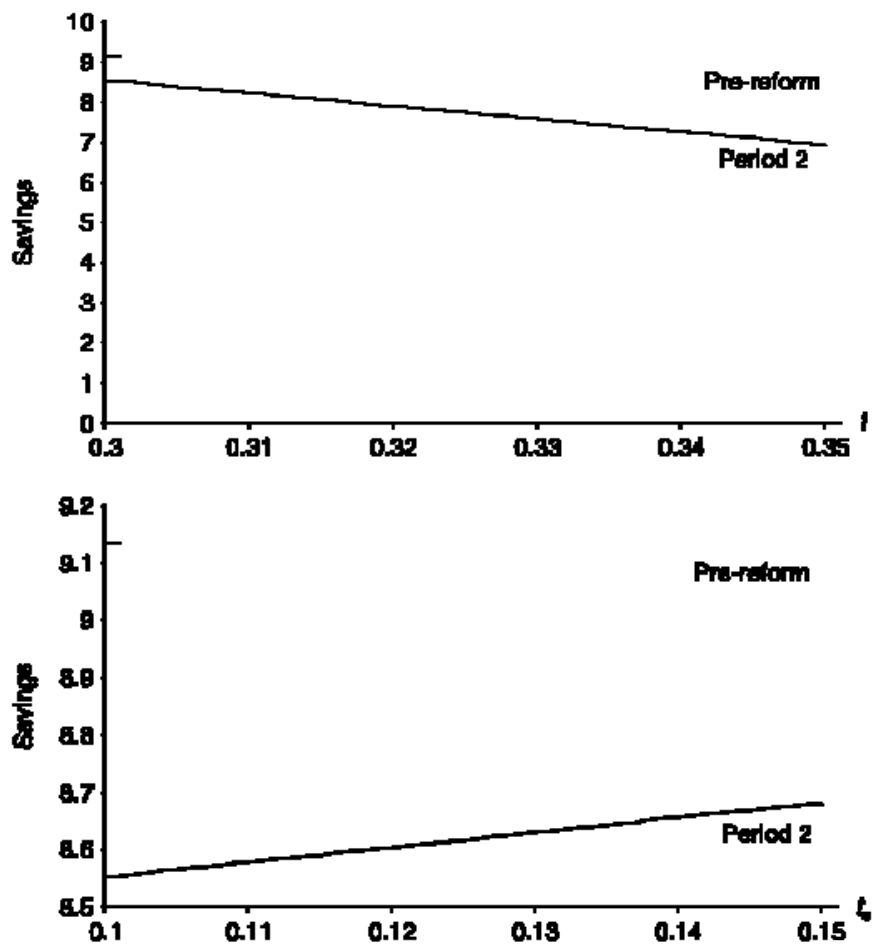

Figure 6. Private savings following move to TTE

of the life cycle when the tax change is made and therefore must, as a result of the unanticipated nature of the policy change, revise the plans previously made which influenced decisions taken in the first period. The model applies to a single individual, and therefore does not allow for any general equilibrium effects - for example, on the wage rate in each period. The analysis has indicated that, even in the context of a highly simplified life cycle model with simple proportional taxes - indeed the basic structure of the model could hardly be simpler - determination of the effects of tax changes is highly complex.

It was nevertheless shown that the partial effects of tax changes, including a superannuation tax change, can be predicted both for those at the beginning and in the middle of the life cycle when the policy change occurs. Allowance was then made for the need to impose a revenue neutral change, and consideration was given to the direction of tax changes arising from the government's budget constraint. It was found that a move from a TTT to a TTE tax structure, requiring a combination of the elimination of the tax on superannuation benefits with an increase in one or more other taxes, has an unambiguous effect on individual private savings, irrespective of the stage in the life cycle when the policy change occurs - private savings fall. However, although the tax shift to TTE on its own increases labour supply, when combined with the income tax or contributions tax increase required for revenue neutrality, the overall effect on labour supply cannot be predicted a priori. It is suggested that the approach taken here provides a useful demonstration of the elements required of a much larger model which might be designed to handle aggregation and general equilibrium considerations. 
Atkinson, M., Creedy, J. and Knox, D. 1996, 'Alternative Retirement Income Strategies: A Cohort Analysis of Lifetime Redistribution’, Economic Record, vol. 72, pp. 97-106.

Australian Government 2006a, 'A Plan to Simplify and Streamline Superannuation’, 9 May 2006, http://www.budget.gov.au/2006-07/overview2/download/overview2.pdf.

2006b, 'A Plan to Simplify and Streamline Superannuation: A Detailed Outline’, May 2006,

http://simplersuper.treasury.gov.au/documents/outline/download/simpler_super.pdf

Creedy, J. 1996, Fiscal Policy and Social Welfare, Cheltenham, Edward Elgar.

Doyle, S., Kingston, G. and Piggott, J. 1999, ‘Taxing Super’, UNSW Retirement Economics Research Paper, no. 12.

Kingston, G. and Piggott, J. 1993, 'A Ricardian Equivalence Theorem on the Taxation of Pension Funds', Economics Letters, vol. 42, pp. 399 - 403.

Knox, D. 1990, A Review of the Options for Taxing Superannuation, Sydney, Australian Tax Research Foundation.

Piggott, J. 1997, ‘Taxation and Pensions', UNSW Retirement Economics Research Paper, no. 7. Whitehouse, E. 1999,

'The Tax Treatment of Funded Pensions', World Bank Social Protection Discus-

sion Paper Series, no. 9910. 